\title{
Fibras de aço em blocos de concreto: estudo para utilização em ambiente marítimo
}

\author{
Steel Fibers in concrete blocks: study for marine \\ environment utilization
}

Migliorini, A.V. ${ }^{1}$; Guimarães, A.T.C. ${ }^{2}$; Ozório, B.P.M. ${ }^{2}$

\author{
${ }^{1}$ Mestranda, Programa de Pós-Graduação em Engenharia Oceânica, FURG, Rio Grande, RS \\ e-mail: alessandramigliorini@gmail.com \\ ${ }^{2}$ Professor Doutor, Escola de Engenharia, FURG, Rio Grande, RS \\ e-mail: atcg@ vetorial.net ; bianca@net.crea-rs.org.br
}

\begin{abstract}
RESUMO
Este projeto tem como propósito de estudo a possibilidade do uso de fibra para os blocos de contenção às ondas marinhas, de modo a influenciar na sua resistência e durabilidade. Levando em consideração o sucesso da utilização da fibra de aço em esgotos sanitários - um ambiente altamente corrosivo - seu uso tornou-se o mais indicado para o ambiente marítimo em questão. Tendo ciência que o concreto pode ser atacado até mesmo sem estar em contato com a água do mar - o ar deste ambiente, por si só, possui sais nocivos à pasta de cimento - foi feito um estudo baseado em um ensaio de durabilidade com blocos (contendo cloreto na massa e sem adição do mesmo) expostos às intempéries e, dentro da mesma análise, ensaio de "molhagem e secagem” utilizando solução de NaCl- para ativar na penetração dos íons cloretos, de modo a verificar a condição da fibra de aço e suas resistências por dois anos de idade.
\end{abstract}

Palavras-chave: ambiente marítimo, fibras de aço, resistência e durabilidade.

\section{ABSTRACT}

The present article's main objective is to study the possibility of using steel fibers in concrete to be applied under the format of blocks for the containment of marine waves, searching to influence their mechanical resistance and lifetime. Based on the success of utilizing steel fibers in concrete applied in sewage, a very corrosive environment, these fibers were also considered to be applied in the marine environment. Concrete might be attacked even without direct contact with sea water because of the high amount of chlorine contained in salts diluted in air. A study was made based on lifetime tests for two years with concrete blocks either containing or not chlorine in its constitution. The concrete blocks were exposed to atmospheric condition and also to a wet-dry testing procedure in the presence of $\mathrm{NaCl}$ to enhance the penetration of chlorine ions in the samples.

Keywords: marine environment; steel fibers; resistance and lifetime.

\section{INTRODUÇÃO}

Visando diminuir custos com as trocas de confecção de novos blocos, este estudo busca elementos que influenciem na durabilidade e resistência dos blocos de concreto utilizados na contenção às ondas marinhas. Para isso, foi feita uma análise do uso da fibra de aço em blocos de concreto expostos ao ambiente marítimo.

Mesmo sabendo que estas estruturas de concreto estão fortemente sujeitas à ação dos íons cloretos quando expostas às atmosferas marinhas, haja vista que os íons podem se deslocar com grande facilidade 
entre os poros do concreto, gerando o início do processo de corrosão [1], quando em contato com as fibras de aço; acredita-se ainda ser esta uma das mais adequadas fibras para tal situação.

Para isso, analisaremos a ação da corrosão nas fibras e, se estas serão absorvidas pelos blocos ou não, podendo até mesmo levar a ruptura do elemento em questão.

Foram realizados ensaios para verificar a influência da fibra de aço quando submetidas à presença forçada de cloreto de sódio no concreto, bem como, o concreto sem a presença do sal. Estes foram submetidos aos ensaios de: tração por compressão diametral e tração na flexão, com a finalidade de comparar as resistências e avaliar se houve perda de resistência pela corrosão das fibras.

\subsection{Patologias}

Após a devida instalação, os blocos podem permanecer estáveis por um longo período de tempo. Porém, devido ao ataque químico do mar, à abrasão da areia transportada pela água, ou ainda, pelo simples atrito entre os mesmos, tais blocos podem se tornar instáveis. Decorrente da violência das ondas, desgaste do material, mal intertravamento dos blocos ou desmoronamento do terreno, os blocos podem apresentar fraturas, decepamento ou até mesmo descaracterização da sua carcaça.

\subsection{Contribuição para a durabilidade dos blocos de concreto utilizados em carapaça de molhes}

Uma contribuição para a durabilidade dos blocos de concreto empregados em ambiente marinho seria o aumento de seu peso, tornando-os mais robustos e propícios a menores deslocamentos. Isto acarretaria num maior consumo de concreto e, consequentemente em maiores gastos para sua confecção e tempo no deslocamento. O que não seria viável, pois aumentaria também o custo com transporte e manuseio destes blocos.

Outra solução seria a adição de fibras ao concreto, tornando-o mais resistente a fim de evitar a quebra brusca do material.

De acordo com a bibliografia pesquisada [2] a fibra de aço seria a mais adequada para tal situação, pois devido à análise de projetos e trabalhos já publicados, este tipo de fibra aumenta consideravelmente a resistência à tração. Logo, verificou-se sua durabilidade em ambiente marítimo devido ao alto índice de cloretos nessa região.

\subsection{Adição de Fibras de Aço}

As fibras de aço inibem a propagação de fissuras no compósito cimentício, atuando como obstáculo ao interceptarem as microfissuras que surgem durante o endurecimento da pasta e evitando o aparecimento prematuro das macrofissuras. No concreto endurecido, limitam o comprimento e a abertura das fissuras, diminuindo também a permeabilidade do concreto, melhorando assim sua durabilidade.

Analisando um concreto simples (sem fibras), como apresentado abaixo, uma fissura irá formar uma barreira à propagação das tensões. O desvio dessas linhas irá implicar numa concentração nas proximidades das fissuras, podendo ocasionar a ruptura abrupta do material e caracterizando assim, um comportamento tipicamente frágil. Devido à utilização das fibras (Figura 1), estas acabam servindo de ponte para a transferência de tensões e, a concentração destas, minimizada [3].
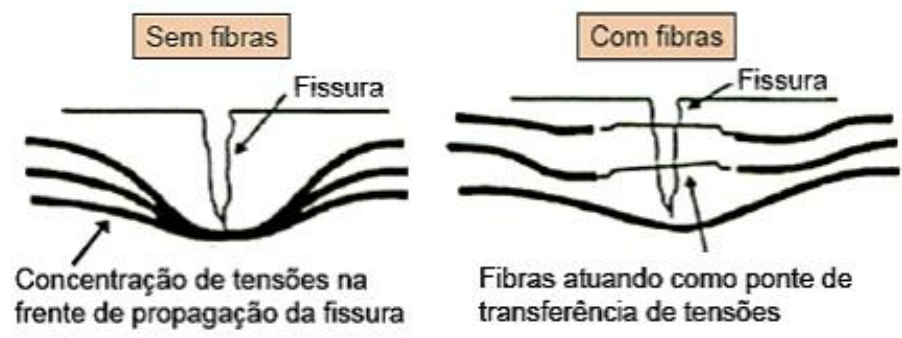

Figura 1: Mecanismo de controle de propagação das fissuras [3]. 
As fibras podem ser adicionadas às matrizes com base de cimento, atuando como reforço primário ou secundário. O reforço primário é utilizado em produtos onde não apresentam as barras de aço convencionais. Nestas aplicações, as fibras atuam para aumentar tanto a resistência quanto a ductibilidade do material. O reforço secundário, utilizados em lajes, pavimentos e tubos de concreto para esgotos sanitários, apresentam a finalidade de controlar e reduzir a fissuração gerada [4].

Se as fibras forem suficientemente resistentes, bem aderidas à matriz cimentícia e, em grande quantidade, estas ajudarão a manter pequena a abertura das fissuras e permitirão ao concreto reforçado com fibras resistir a tensões de tração bem elevadas, com grande capacidade de deformação no estágio pósfissuração (o chamado "strain softening”) [5].

O maior benefício obtido em reforçar uma matriz frágil com fibras é o de alterar o seu comportamento após a fissuração. O compósito, ao invés de romper-se após o início da fissura da matriz, pode apresentar uma deformação plástica considerável, tornando-o, assim, um material adequado para a construção. Para que isso aconteça, as fibras devem ser adicionadas em volume, comprimento e formatos adequados [6].

\subsection{Estudo da Fibra}

Seu uso difundiu-se na década de 80 e, desde então são muito utilizadas em pavimentos rodoviários, aeroportos, estradas ou túneis de estradas, ferrovias, concreto projetado para túneis [7], escoramentos de escavações subterrâneas e a céu aberto, em pré-moldados e estruturas de concreto armado convencional [8], com o objetivo de diminuir a espessura das lajes e reduzir a fissuração.

O Concreto Reforçado com Fibras de Aço (CRFA) é um compósito caracterizado por apresentar cimento hidráulico, agregados graúdos e miúdos e, pequenas fibras de aço dispersas e descontínuas.

Além de proporcionar a diminuição das fissuras, as fibras de aço possuem alta resistência e alto módulo de elasticidade. Atuam como reforço do concreto endurecido, podendo até substituir total ou parcialmente as telas e barras de aço usadas convencionalmente em algumas concretagens, tornando-se mais eficientes, econômicas, e de fácil e rápida aplicação quando comparadas às soluções tradicionais [4].

Nos últimos trinta anos, estudos realizados comprovaram que as fibras de aço são altamente eficazes na substituição das armaduras convencionais. Drenagens pluviais, bueiros, travessias [9], e até mesmo tubos para esgoto sanitário, onde o ambiente é propício à contaminação e desgastes por efluentes químicos, apresentaram uma significativa capacidade de suporte pós-fissuração e ótimos ganhos de durabilidade [10].

\subsection{Normatização Brasileira}

Visando à padronização, foram publicadas pela ABNT em 2007, quase que simultaneamente, regras sobre a especificação de fibras de aço (NBR 15530:07) e a atualização da norma NBR 8890 - Tubo de concreto, de seção circular, para águas pluviais e esgotos sanitários [11]. A nova norma, intitulada "Fibras de aço para concreto - Especificação", trata da classificação das fibras de aço e dimensiona os padrões mínimos: sua forma geométrica, tolerância aos defeitos de fabricação, resistência à tração e, também, ao dobramento das fibras. Todavia, esta norma é estabelecida apenas ao produto final, não enfatizando o desempenho da mesma quando adicionada ao concreto, pois isso depende do consumo de fibras e da resistência da matriz [4].

\section{MATERIAIS E MÉTODOS}

O objetivo deste trabalho é estudar o comportamento das fibras frente ao ataque por cloretos, verificando se há corrosão e, em havendo corrosão, o quanto afeta a resistência do concreto.

\subsection{Ensaio de Durabilidade}

O termo durabilidade de um material refere-se ao seu tempo de vida útil sob condições ambientais préestabelecidas, ou seja, a durabilidade do concreto de cimento Portland é definida como a sua capacidade de resistir à ação das intempéries, ataques químicos, abrasão ou qualquer outro processo de deterioração [14].

O traço do concreto utilizado nestes experimentos foi de 1:2,12:2,88 (c:a:b), com relação a/c $=0,54$, de modo a obter-se uma resistência próxima ao dos Tetrápodes utilizados nos molhes da barra de Rio Grande durante a sua recuperação [10]. 
Foram realizadas duas "betonadas”: a primeira com adição de fibra de aço e 1\% de cloreto de sódio (NaCl-) em relação ao peso de cimento - destinada para armazenamento e desgaste ao ar livre ("Ensaio de exposição ás intempéries), conforme Fig. 2.
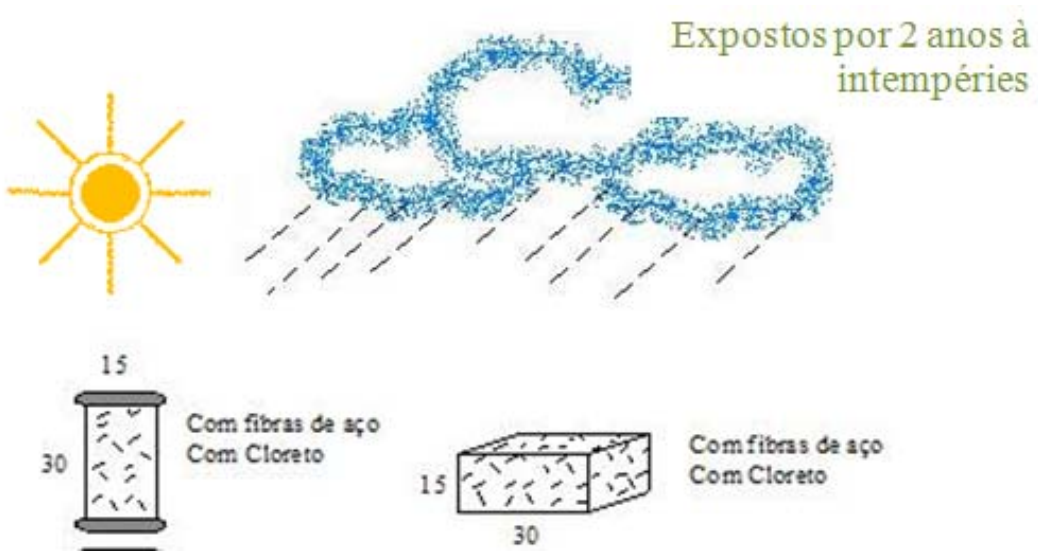

Figura 2: Exposição natural do concreto com fibra de aço.

Por fim, na segunda "betonada”, utilizou-se somente a fibra de aço para a submissão de banhos de “molhagem e secagem” em laboratório.

Para tais, foram realizados os ensaios de caracterização do material, descritos a seguir.

\subsection{Caracterização do Material}

\subsubsection{Cimento}

O cimento utilizado foi o CP-IV.

Foram realizados ensaios de módulo de finura, pasta de consistência normal, tempo de pega, densidade e compressão. Os resultados são apresentados nas tabelas abaixo.

Tabela 1: Resultados dos ensaios de caracterização do cimento.

\begin{tabular}{c|c|c}
\hline ENSAIO & NORMA ABNT & RESULTADOS \\
\hline Módulo de Finura & NBR MB 3432 (1991) [12] & $\mathbf{F}=\mathbf{0 , 5 8 \%}$ \\
\hline Pasta de Consistência Normal & NBR NM 43 (2003) [13] & A = 33\% de água \\
\hline Tempo de Pega & NBR NM 43 (2003) [13] & Início de Pega = 5:40 h \\
\cline { 3 - 3 } & & Fim de pega = 8:16 h \\
\hline Densidade & NBR NM 23 (2001) [14] & Média das leituras = 2,73 \\
\hline
\end{tabular}

Tabela 2: Resistência à compressão do cimento CPIV-32 [MPa] [15].

\begin{tabular}{c|c|c|c}
\cline { 2 - 4 } & 3 DIAS & 7 DIAS & 28 DIAS \\
\hline CP 1 & 14,92 & 17,82 & 25,97 \\
\hline CP 2 & 17,42 & 21,39 & 31,83 \\
\hline CP 3 & 17,21 & 19,45 & 34,63 \\
\hline CP 4 & 19,25 & 20,68 & 33,61 \\
\hline CP 5 & 17,42 & 21,39 & 26,23 \\
\hline CP 6 & 15,07 & 21,29 & 32,34 \\
\hline MÉDIA & $\mathbf{1 6 , 8 8}$ & $\mathbf{2 0 , 3 4}$ & $\mathbf{3 0 , 7 7}$ \\
\hline
\end{tabular}


Nota-se que o cimento não alcança a resistência mínima exigida por norma de $32 \mathrm{MPa}$, no entanto para efeito de observação do benefício das fibras, este fato não prejudica a análise final.

\subsubsection{Areia}

As amostras foram secas por 24 horas em estufa a $100^{\circ} \mathrm{C}$.

A Tabela 3 apresenta a média da quantidade de material retido por cada uma das malhas.

Tabela 3: Média granulométrica da areia [16].

\begin{tabular}{c|c|c|c|c|c}
\hline \multicolumn{5}{c}{ MÉDIA GRANULOMÉTRICA DA AREIA } \\
\hline \multirow{2}{*}{$\mathbf{N}^{\circ}$} & PENEIRAS & AMOSTRA & $\%$ & $\%$ & $\%$ \\
\cline { 2 - 6 } & ABERTURAS & MATERIAL & RETIDO & ACUMULADO & RETIDO \\
\hline \multirow{2}{*}{$3 / 8 "$} & 9,5 & {$[\mathbf{g}]$} & & & acumulada \\
\hline \multirow{2}{*}{4} & 4,8 & 0 & 0 & 100 & 0 \\
\hline 8 & 2,4 & 4,15 & 0,34 & 99,66 & 0,34 \\
\hline \multirow{2}{*}{16} & 1,2 & 321,42 & 26,71 & 67,49 & 32,51 \\
\hline \multirow{2}{*}{30} & 0,6 & 387,75 & 32,22 & 35,33 & 64,72 \\
\hline \multirow{2}{*}{50} & 0,3 & 287,75 & 23,91 & 11,37 & 88,63 \\
\hline 100 & 0,15 & 118,55 & 9,85 & 1,52 & 98,48 \\
\hline 200 & 0,075 & 10,56 & 0,87 & 0,65 & 99,35 \\
\hline & Resíduo & $\mathbf{7 , 7 8}$ & $\mathbf{0 , 6 5}$ & $\mathbf{0}$ & $\mathbf{1 0 0}$ \\
\hline & TOTAIS & $\mathbf{1 2 0 3 , 6 8}$ & $\mathbf{1 0 0}$ & $\mathbf{1 0 0}$ & $\mathbf{4 8 9 , 8 3}$ \\
\hline
\end{tabular}

A Tabela 4 apresenta o resultado dos ensaios de massa específica absoluta, massa específica aparente e impurezas para a caracterização da areia.

Tabela 4: Resultados dos ensaios de caracterização da areia.

\begin{tabular}{c|c|c}
\hline ENSAIO & NORMA ABNT & RESULTADOS \\
\hline Massa Específica Absoluta & NBR NM 52 (2003) [17] & $\mathrm{g}=2,60 \mathrm{~g} / \mathrm{cm}^{3}$ \\
\hline Massa Específica Aparente & NBR NM 52 (2003) [17] & $\mathrm{g}=1,54 \mathrm{~g} / \mathrm{cm}^{3}$ \\
\hline Impurezas & NBR NM 49 (2001) [18] & superior a 300 partes por milhão \\
\hline
\end{tabular}

\subsubsection{Brita}

O agregado graúdo utilizado foi brita 1.

As amostras foram secas em estufa para a realização do experimento.

A Tabela 5 apresenta a média da quantidade de material retido por cada uma das malhas. 
Tabela 5: Média granulométria da brita [16].

\begin{tabular}{|c|c|c|c|c|c|}
\hline \multicolumn{6}{|c|}{ MÉDIA GRANULOMÉTRICA DA BRITA } \\
\hline \multicolumn{2}{|c|}{ PENEIRAS } & \multirow{2}{*}{$\begin{array}{c}\text { AMOSTRA } \\
\text { MATERIAL } \\
\text { [g] }\end{array}$} & \multirow{2}{*}{$\begin{array}{c}\% \\
\text { RETIDO }\end{array}$} & \multirow{2}{*}{$\begin{array}{c}\% \\
\text { ACUMULADO }\end{array}$} & \multirow{2}{*}{$\begin{array}{c}\% \\
\text { RETIDO } \\
\text { ACUMULADA }\end{array}$} \\
\hline $\mathbf{N}^{\circ}$ & $\begin{array}{c}\text { ABERTURAS } \\
\text { em mm }\end{array}$ & & & & \\
\hline & 76 & 0 & 0 & 100 & 0 \\
\hline & 38 & 0 & 0 & 100 & 0 \\
\hline & 19 & 30,09 & 0,6 & 99,4 & 0,6 \\
\hline 3/8" & 9,5 & 4030,15 & 80,79 & 18,61 & 81,39 \\
\hline 4 & 4,8 & 746,55 & 14,97 & 3,64 & 96,35 \\
\hline 8 & 2,4 & 75,43 & 1,51 & 2,13 & 97,87 \\
\hline 16 & 1,2 & 18,7 & 0,37 & 1,76 & 98,24 \\
\hline 30 & 0,6 & 11,58 & 0,23 & 1,53 & 98,47 \\
\hline 50 & 0,3 & 8,27 & 0,17 & 1,36 & 98,64 \\
\hline \multirow[t]{2}{*}{100} & 0,15 & 18,02 & 0,36 & 1 & 99 \\
\hline & $<0,15$ & 49,88 & 1 & 0 & 100 \\
\hline \multicolumn{2}{|r|}{ TOTAIS } & 4988,64 & 100 & 100 & 870,57 \\
\hline
\end{tabular}

A Tabela 6 apresenta o resultado dos ensaios de massa específica absoluta e massa específica aparente para a caracterização da brita.

Tabela 6: Resultados dos ensaios de caracterização da brita.

\begin{tabular}{l|c|c}
\hline \multicolumn{1}{c|}{ ENSAIO } & NORMA ABNT & RESULTADOS \\
\hline Massa Específica Absoluta & NBR NM 53 (2003) [19] & $\mathrm{g}=2,68 \mathrm{~g} / \mathrm{cm}^{3}$ \\
\hline Massa Específica Aparente & NBR NM 53 (2003) [19]] & $\mathrm{g}=4,33 \mathrm{~g} / \mathrm{cm}^{3}$ \\
\hline
\end{tabular}

\subsection{4. Água}

A água utilizada é potável, proveniente da rede de abastecimento da Companhia Rio-Grandense de Abastecimento (CORSAN), da cidade de Rio Grande.

\subsubsection{Fibra}

Foi utilizada no estudo uma única fibra de aço com ancoragem em gancho. De formato longitudinal igual a $60 \mathrm{~mm}$ e uma seção transversal de $0,75 \mathrm{~mm}$, resultou num fator de forma de 80.

O teor utilizado foi de $30 \mathrm{~kg}$ por metro cúbico de concreto, o equivalente a $4600 \mathrm{~g}$ de aço à mistura. A quantidade de fibra foi selecionada a partir da revisão da literatura pesquisada sobre estudos preliminares. 


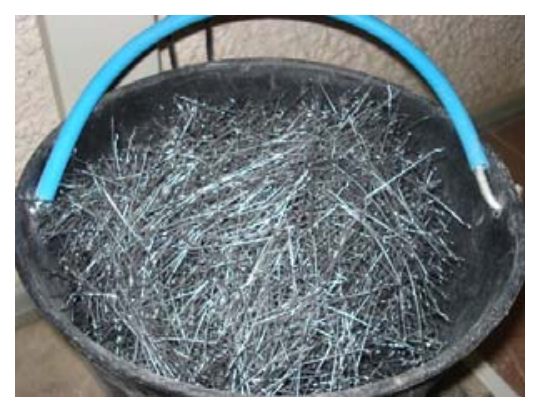

Figura 3: Fibras de aço utilizadas no ensaio.

A fibra de aço é da marca Harex KSF 60 / 0,75, produzida pela Vulkan do Brasil Ltda.

\subsubsection{Aditivo}

Utilizou-se nos ensaios o aditivo plastificante multifuncional TEC-MULT 440 LF, da marca Rheotec, pronto para o uso e isento de cloretos.

Este aditivo, usado corretamente, proporciona ao concreto grande redução do teor de ar incorporado, melhora a trabalhabilidade e o aumento na resistência final, resultando numa maior durabilidade.

\subsection{Ensaio de exposição às intempéries}

Para este ensaio, os corpos-de-prova foram submetidos às intempéries, expostos no Campus Cidade da Universidade Federal do Rio Grande - FURG, no qual foram feitos ensaios para a verificação da sua resistência após 90 e 730 dias de concretados.

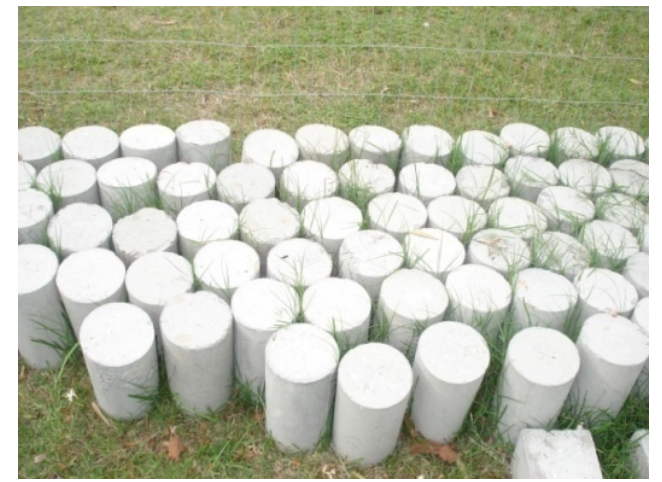

Figura 4: Estocagem dos corpos-de-prova expostos a intempéries.

\subsection{Ensaio de "secagem e molhagem"}

$\mathrm{O}$ efeito de secagem e molhagem tem capacidade de aumentar a intensidade de ataque por cloretos nos corpos-de-prova.

Para isso, os blocos foram imersos em solução de cloreto de sódio a uma concentração de $3 \%$ do volume de água, durante quatro dias. Após esse período passaram por um processo de secagem nos três dias correntes, no mesmo ambiente, completando ciclos semanais. 


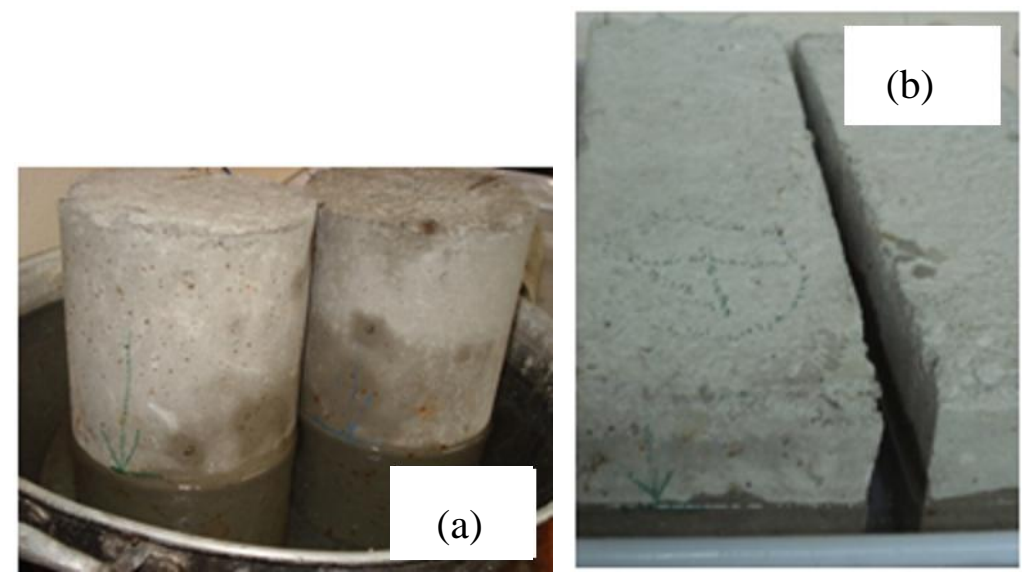

Figura 5: Cp’s em processo de molhagem para os ensaios de verificação da resistência à: (a) compressão diametral e (b) tração na flexão.

As primeiras resistências foram obtidas aos 90 dias, tendo a continuidade do ensaio até os 2 anos de idade.

\section{APRESENTAÇÃO E ANÁLISE DOS RESULTADOS}

Os resultados foram analisados visando comparar o desempenho do concreto com fibras de aço (teor de 30\%) nas datas de 90 dias e 2 anos de ensaio. Foi observado eventual perda de resistência até os 2 anos e visualmente foi observado se houve fissuração, lascamento ou manchas. Na ocorrência de manchas, foi analisado se o produto da corrosão foi absorvido pela rede de poros do concreto, ou se a expansão desta poderia provocar fissuras.

\subsection{Resultados do ensaio de exposição às intempéries}

As tabelas abaixo apresentam os resultados dos ensaios para os blocos expostos à condições de intempéries diversas.

Tabela 7: Resultados dos ensaios de compressão diametral e tração na flexão aos 90 e 730 dias, para a betonada 1 (concreto com cloreto de sódio).

\begin{tabular}{cc|c} 
& \multicolumn{2}{c}{ Betonada 1 - Diametral } \\
\cline { 2 - 3 } & \multicolumn{2}{c}{$\mathrm{ft}, \mathrm{D}$} \\
\hline 90 dias & 730 dias \\
\hline 2,69 & 3,08 \\
Média & 2,98 & 3,42 \\
\cline { 2 - 3 } & 2,83 & 3,25
\end{tabular}

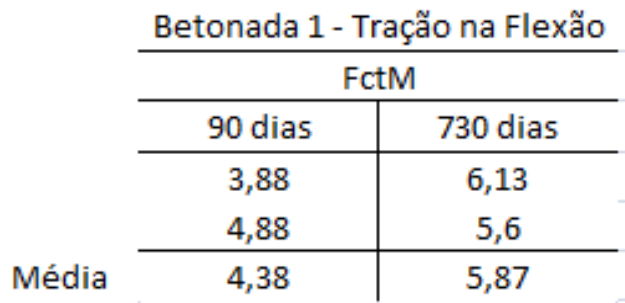

De acordo com o gráfico apresentado e considerando as médias obtidas, nota-se que a resistência à compressão diametral aumentou em $14,84 \%$ no intervalo de 640 dias e a resistência à tração na flexão obteve um acréscimo de 34,02\% para o mesmo período. Não foram verificadas, em momento algum, perdas de resistência com os corpos-de-prova com adição de fibras de aço e $1 \%$ de NaCl- na massa do concreto, quando sujeitos à exposição ao ambiente marítimo.

Com a análise visual realizada nos corpos-de-prova, pode-se verificar uma pequena quantidade de manchas oriundas da oxidação das fibras de aço. Estas, por serem em pequenas quantidades e somente superficiais foram absorvidas pela rede de poros do concreto 


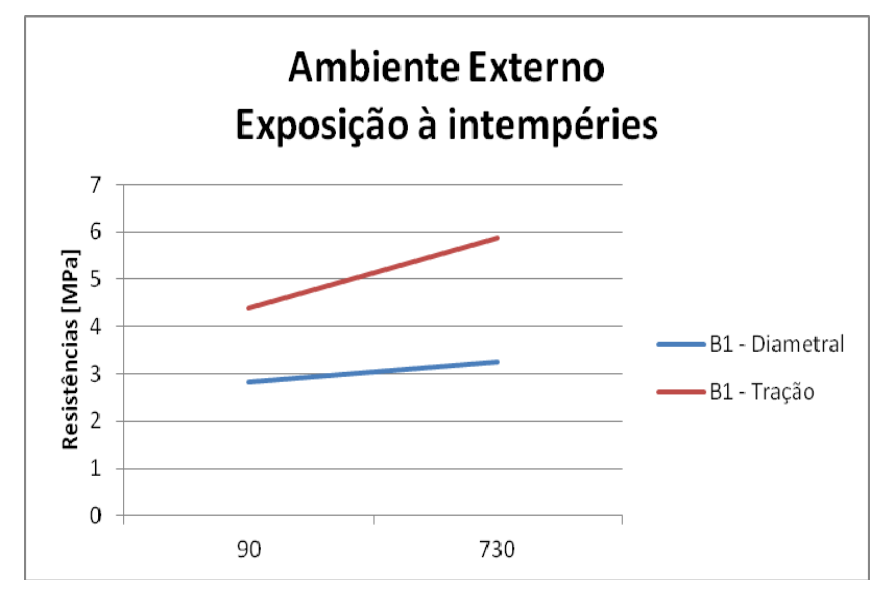

Figura 6: Análise das resistências dos corpos-de-prova expostos ao ambiente marítimo com adição de cloreto.

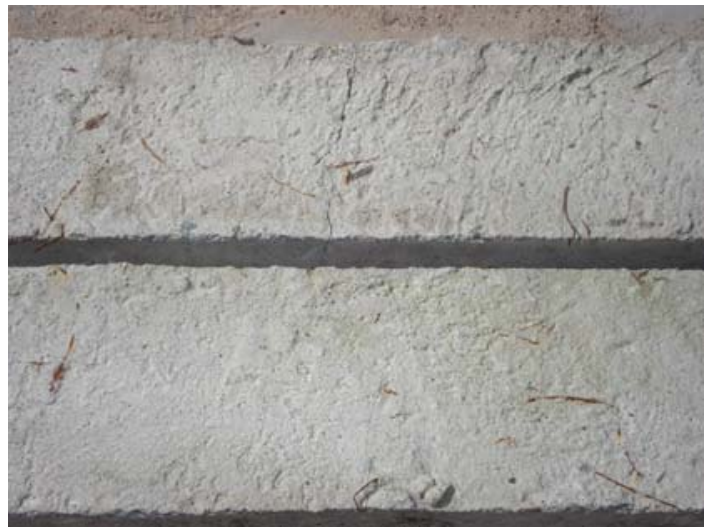

Figura 7: Análise visual do corpo-de-prova exposto à intempéries por dois anos.

\subsection{Resultados do ensaio de "molhagem e secagem"}

A tabela a seguir apresenta os resultados dos ensaios para os blocos sujeitos ao ensaio controlado de "secagem e molhagem".

Tabela 8: Resultados dos ensaios de compressão diametral e tração na flexão aos 90 e 730 dias, para a betonada 3 (concreto com cloreto de sódio).

\begin{tabular}{cc|c} 
& \multicolumn{2}{c}{ Betonada 2 - Diametral } \\
\cline { 2 - 3 } & \multicolumn{2}{c}{$\mathrm{ft}, \mathrm{D}$} \\
\hline 90 dias & 730 dias \\
\hline 3,22 & 3,83 \\
Média & 3,08 & 3,09 \\
\cline { 2 - 3 } & 3,15 & 3,46
\end{tabular}

\begin{tabular}{|c|c|}
\hline \multicolumn{2}{|c|}{ FctM } \\
\hline 90 dias & 730 dias \\
\hline 4,77 & 5,6 \\
\hline 4,85 & 5,73 \\
\hline 4,81 & 5,66 \\
\hline
\end{tabular}




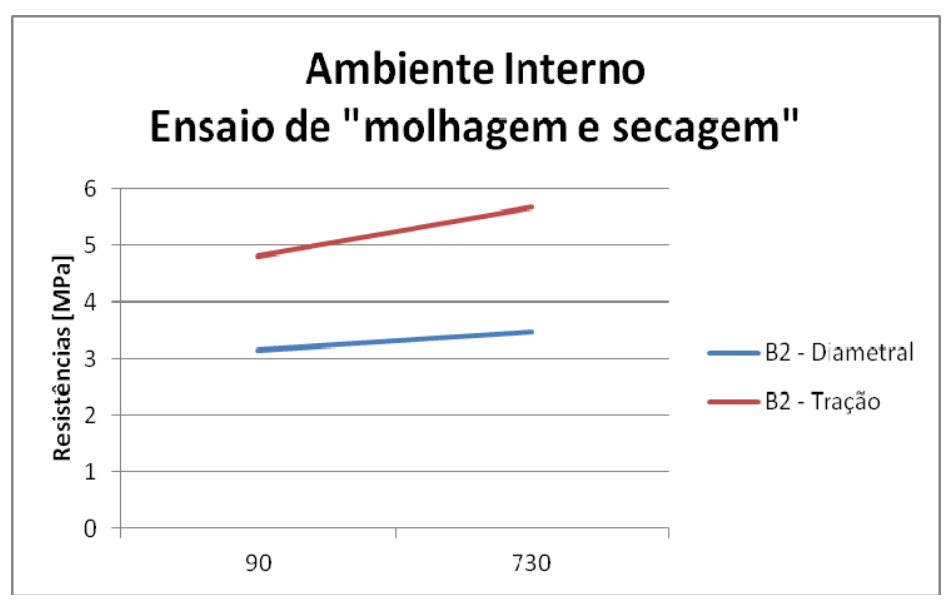

Figura 8: Análise das resistências dos corpos-de-prova armazenados em ambiente interno controlado.

De acordo com o gráfico apresentado e considerando as médias obtidas, pode-se notar que a resistência à compressão diametral aumentou em 9,84\% no intervalo de 640 dias e, a resistência à tração na flexão obteve acréscimo de $17,67 \%$ para o mesmo período. Novamente, não foram constatadas perdas de resistência com os corpos-de-prova com adição de fibras de aço, mesmo quando sujeitos ao ensaio de molhagem e secagem acelerada.

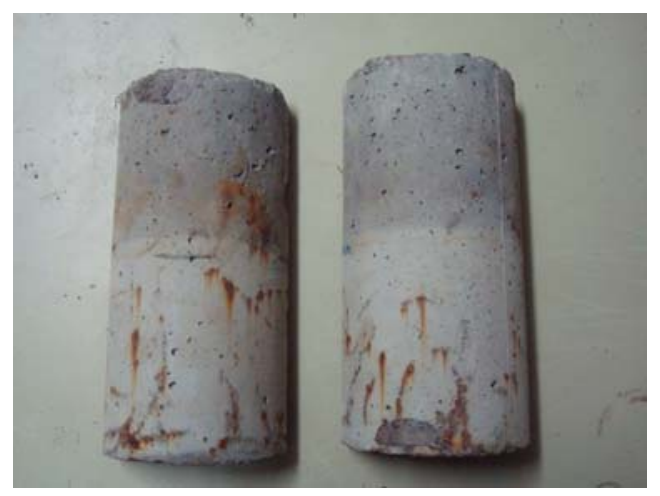

Figura 9: Análise das manchas em cp, após dois anos de molhagem e secagem, sujeito ao ensaio de compressão diametral.

Conforme a Figura 9 apresentada, constata-se que a quantidade maior de manchas provenientes da oxidação das fibras de aço encontra-se na zona em que o cp não estava sujeito a ação de molhagem e secagem, e sim, à parte que ficou fora da água. Novamente, estas manchas foram somente superficiais, não comprometendo a resistência do concreto (Figura 10).

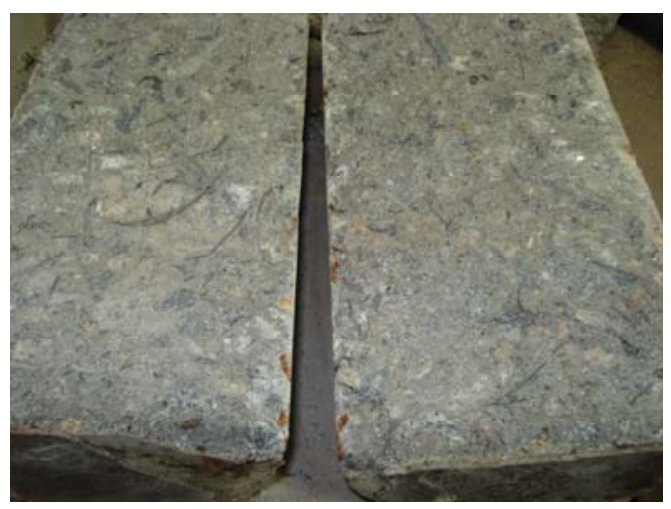

Figura 10: Análise visual da situação das fibras de aço no interior do concreto, após dois anos de ensaio. 


\subsection{Comparativo entre os resultados}

A Figura 11 apresenta os resultados comparativos entre o ambiente externo e interno.

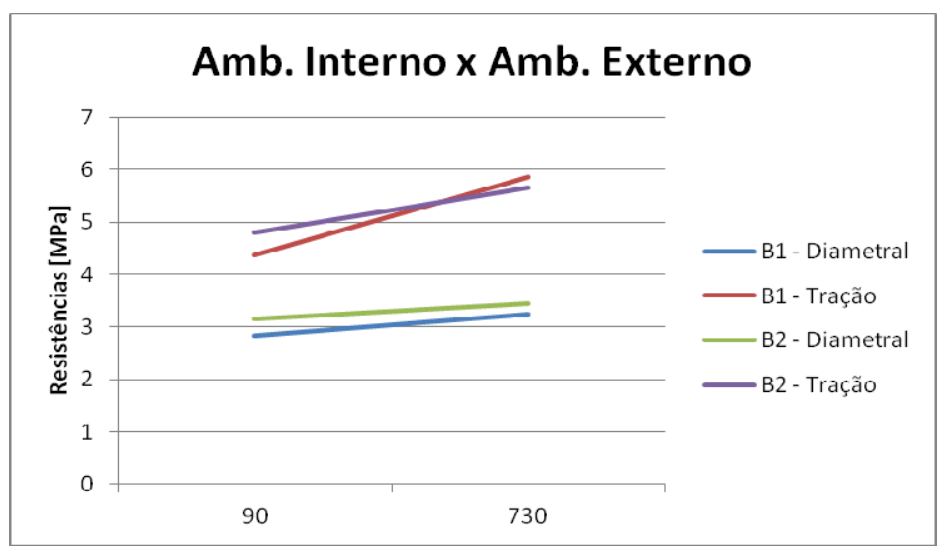

Figura 11: Comparação dos ensaios de compressão diametral e tração na flexão aos 90 e 730 dias em ambiente interno e externo.

Analisando o gráfico acima, para os 90 dias de ensaio (análise por compressão diametral) - pode-se verificar um aumento na resistência de $11,31 \%$ do ambiente interno para o externo. Já aos 2 anos de ensaio, esta resistência ficou 6,46\% superior também no ambiente interno "controlado".

Para o ensaio de tração na flexão, aos 90 dias de andamento, o ambiente interno obteve um acréscimo na resistência de $9,82 \%$, enquanto que para os 2 anos de ensaio, o ambiente externo obteve acréscimo de 3,58\% em relação aos ensaios de “secagem e molhagem” semanais.

Embora a pigmentação por ferrugem ter sido aparentemente mais que o dobro para o ambiente interno, esta não comprometeu na resistência do concreto. Para o mesmo concreto analisado em diferentes ambientes, pode-se constatar que os corpos-de-prova expostos às intempéries não sofreram com as condições climáticas e, os cp’s armazenados em laboratório, em constantes ensaios de imersão em cloreto de sódio a $3 \%$ e secagem no mesmo local, não depreciaram tanto na sua durabilidade quanto na sua resistência.

\section{CONCLUSÕES}

A proposta deste artigo foi analisar a durabilidade da adição de fibras de aço nas estruturas de concreto expostas ao ambiente marítimo, através da análise da resistência desses elementos. Desse modo, o estudo veio apresentar uma nova potencialidade de aplicação para o concreto reforçado com fibras de aço, tendo como intenção o melhoramento das propriedades de resistência do concreto utilizado na confecção dos blocos de concreto tetrápodes, blocos de concreto pré-moldados utilizados nos molhes da Barra do Rio Grande, visando reduzir os custos de manutenção e prolongando a vida útil desses blocos.

Devido ao fato das fibras não receberem nenhum tratamento especial para evitar a corrosão, verificase que a sua durabilidade está condicionada ao seu confinamento no meio altamente alcalino que é a matriz de cimento, fato este confirmado, visto que mesmo com um ataque intenso por "molhagem e secagem” ou pela adição de cloreto na massa, não foi observada corrosão significativa nas fibras.

Em suma, a viabilidade da adição das fibras de aço é comprovada pela melhoria das propriedades de resistência do concreto. Assim, sugere-se para as substituições futuras dos blocos - ou em novo molhe a ser construído - que estas sejam feitas por tetrápodes com fibras para pontos estratégicos (não em linha d’água, nem quando submersos e sim em pontos de maiores choques das correntes nos mesmos), proporcionando uma maior durabilidade e diminuindo custos com trocas relacionadas a transportes e manuseios, quando comparados ao tempo durável destes no local de função ou inseridos ao ambiente marítimo.

\section{AGRADECIMENTOS}

A CAPES pelo apoio financeiro. 


\section{BIBLIOGRAFIA}

[1] SANTOS, L., DE CARVALHO, A. L., CARDOSO, R. J. C, et al., “Avaliação do graus de penetração do cloreto no concreto de cimento Portland contendo pó de aciaria elétrica”, Universidade Federal da Bahia/EP. Disponível em: http://www.abraco.org/23sconc.htm. Acessado em 22, fevereiro de 2009.

[2] MIGLIORINI, A.V., Estudo para fibras em blocos de concreto utilizados em carapaça de molhes de barra. Projeto de Graduação do Curso de Engenharia Civil - FURG. Rio Grande, 2007.

[3] SCOARIS, M.R., BARBOSA, M.P., PINTO JR., N.O; “Avaliação da resistência e rigidez de concretos reforçados com fibras submetidas à cura térmica pelo método da maturidade”, e-Mat - Revista de Ciência e Tecnologia de Materiais de Construção Civil, vol. 2, pp. 127-141, novembro, 2005.

[4] FIGUEIREDO, A.D, 'Concreto com fibras. Concreto - Ensino, Pesquisas e Realizações”, In: IBRACON Instituto Brasileiro do Concreto, pp. 1195 - 1225, São Paulo, 2005.

[5] THOMAZ, E.C.S., Concreto reforçado com fibras - mito e realidade, Notas de aula, Instituto Militar de Engenharia (IME). pp. 1-13. Rio de Janeiro, s/ ano.

[6] FUGII, A.P., AKASAKI, J.L., SALLES, F.M., “Tubos de concreto reforçados com fibras de aço”, In: 49 Congresso Brasileiro do Concreto - CBC2007 - 49CBC0162. IBRACON. Bento Gonçalves, 2007.

[7] MACCAFERRI. http://www.maccaferri.com.br . Acessado em 16, fevereiro de 2009.

[8] ABTC - Associação Brasileira dos Fabricantes de Tubos de Concreto. Soluções de Infra-Estrutura em Tubos de Concreto. CD-ROM. Setembro, 2003.

[9] MEHTA, P.K., MONTEIRO, P.J.M., Concreto: Estrutura, propriedades e materiais, Editora Pini Ltda., São Paulo, 1994.

[10] RAMOS, M.F., PINTO JÚNIOR, N.O.P., FRANCO, B.L.M., “Avaliação de tubos de concreto reforçado com fibras de aço submetidos ao ensaio de compressão diametral”. In: $49^{\circ}$ Congresso Brasileiro do Concreto - CBC2007 - 49CBC0026. IBRACON. Bento Gonçalves, 2007.

[11] FIGUEIREDO, A.D., NETO, P.J.C., FARIA, H.M., “Aço em Obras de Concreto. A nova normalização brasileira sobre fibras de aço”, Revista Concreto e Construções. IBRACON - Instituto Brasileiro do Concreto, Ano XXXVI. n. 50. pp. 67 - 75, abril - junho, 2008.

[12] ABNT - Associação Brasileira de Normas Técnicas, MB 3432: Cimento Portland - Determinação da finura por meio da peneira $75 \mu \mathrm{m}$ ( $\mathrm{n}^{\circ}$ 200) (Procedimento), Rio de Janeiro, julho de 1991.

[13] ABNT - Associação Brasileira de Normas Técnicas, NBR NM 43: Cimento Portland - Determinação da pasta de consistência normal. (Procedimento), Rio de Janeiro, julho de 2002.

[14] ABNT - Associação Brasileira de Normas Técnicas, NBR NM 23: Cimento Portland e outros materiais em pó - Determinação da massa específica (Procedimento), Rio de Janeiro, maio de 2001.

[15] ABNT - Associação Brasileira de Normas Técnicas, NBR 7215: Cimento Portland - Determinação da resistência à compressão (Procedimento), Rio de Janeiro, dezembro de 1996.

[16] ABNT - Associação Brasileira de Normas Técnicas, NBR NM 248: Agregados - Determinação da composição granulométrica (Procedimento), Rio de Janeiro, julho de 2003. 6 págs.

[17] ABNT - Associação Brasileira de Normas Técnicas. NBR NM 52: Agregado miúdo - Determinação da massa específica e massa específica aparente (Procedimento). Rio de Janeiro, julho de 2003.

[18] ABNT - Associação Brasileira de Normas Técnicas, NBR NM 49: Agregado miúdo - Determinação de impurezas orgânicas (Procedimento), Rio de Janeiro, 2001.

[19] ABNT - Associação Brasileira de Normas Técnicas, NBR NM 53: Agregado graúdo - Determinação de massa específica, massa específica aparente e absorção de água (Procedimento), Rio de Janeiro, julho de 2003. 